\section{The 'German synthetics'}

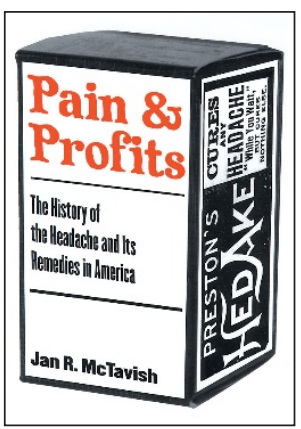

\section{Pain and Profits: The History of the Headache and Its Remedies in the United States}

\section{by Jan McTavish}

Rutgers University Press, 2004

239 pp., paperback, $\$ 23.95$

ISBN 0813534410

\section{Reviewed by Lawrence Robbins}

In Pain and Profits Jan McTavish takes the reader on a fascinating trek through two centuries of headache, pharmacy and medicine. Throughout the book, McTavish reveals that many of our current questions and ethical quandaries surrounding drug use are not so new. For example, we worry that the pharmaceutical industry has undue influence on physicians through advertisements and promotions; these fears were present during the late 1880s as well.

Oddly enough, during the nineteenth century headache was treated more seriously than in more modern times. Headache was viewed as a legitimate, medical illness; not as a mainly psychological phenomenon, a concept common in the mid-1900s that fortunately has fallen largely out of favor. During the 1800s, remedies ranged from squeezing a mole to local applications of substances such as peppermint - still used todayto the head or feet. At Appomatox, where the Union won the American civil war, Ulysses S. Grant used mustard foot baths to direct toxins from the head to the feet-although it is possible that the surrender of Robert E. Lee eventually eased the general's pain. Other commonly used options included bromides, cannabis, caffeine and bloodletting with leeches. Patients' expectations of relief were low.

For serious headaches, opium and morphine were options; but, as today, there was a bias against prescribing these powerful opioids, considered too precious for a mere headache. Nonetheless, during the late $1800 \mathrm{~s}$ the US per capita opiate consumption was higher than any other country, similar to the situation today.

Finally, there were the patent medicines, high in sugar and alcohol content, and some $5 \%$ laced with narcotics or cannabis. These concoctions were marketed directly to the public for a range of ailments. Spending on them had reached 50 million dollars by 1900, and there were no regulations or laws governing the advertisements - as with the largely unregulated herbal industry today. Furthermore, the 'drug lobby' for the patent medicine makers was powerful and the ingredients were usually kept secret. Even today, the label on a herbal remedy may not correspond with exactly what is inside the bottle. Throughout the era of patent medicines, drug patents were felt to be unethical and 'held the public hostage.' 'Ethical' companies did not advertise directly to the public. But doctors

Lawrence Robbins is in the Department of Neurology, Rush Medical College, Chicago, Illinois, and the Robbins Headache Clinic, Northbrook, Illinois, USA. e-mail: Irobb98@aol.com were another story: by the 1870 s, there were 70 medical schools in the United States, although medical training was weak and anyone could claim to be a doctor. And, as they are today, doctors were, as McTavish writes, "flattered by the free samples and all the attention" brought by "well-dressed salesmen, making claims about the drug." Undue influence by pharmaceutical advertisements in journals was assailed, and advertisements and drug company representatives were chief sources of medical information for the physicians. Finally in the early 1900s, Congress began to enact drug laws.

Even before 1900, the influence of patent medicines had begun to erode, as outstanding German organic chemists were busy synthesizing new drugs (and obtaining patents). In 1874, the first effective synthetic antifever medication, salicylic acid, was produced. The Germans had performed studies on patients, but these studies suffered from poor design and produced no real statistics. In 1887, Phenacetin, another aspirinrelated compound, was introduced by Bayer to aid pain and fevers.

Doctors were often reluctant, for a number of reasons, to prescribe the new pain medication and patients often obtained the drugs directly from pharmacies. Mixing, rolling and compounding were tough jobs, and the pharmacists rarely received very much credit. The apothecaries could not make a living by filling scripts, accounting for the appearance of soda fountains in the drug stores.

In the early twentieth century, aspirin, like most drugs, was much more expensive in the United States than elsewhere. Smuggling Phenacetin or aspirin from Canada became a big business-although the illicit drugs were often fakes, consisting of compounds such as talcum powder. Factory-packaged and premeasured Bayer aspirin, on the other hand, was considered safe. As a group, the 'German synthetics' were considered fairly harmless for decades, until it became clear that overuse led to stomach ulcers, kidney failure and other problems.

Aspirin was awarded a patent in 1900, and the phrase 'take aspirin and call me in the morning' was coined shortly thereafter. Bayer aggressively sued when others infringed upon their patents. After World War II, the company was sold to another company, which advertised heavily in newspapers for remedies for headaches and other ills. By 1920, aspirin had become the top-selling drug worldwide. With its uses to help with pain, cancer, heart disease and stroke, aspirin remains the number one drug used today.

As medical science progressed in many areas, headache research lagged behind. By 1940, gastrointestinal causes were still thought to be prominent in the evolution of headache. Doctors remained reluctant to prescribe pain relievers, and psychiatric causes were unfortunately a popular concept. Migraine patients were considered neurotic, and the 'migraine personality' was frequently discussed. Ergots, natural drugs derived from a fungus, were discovered to aid migraine in the 1920s, but the next significant breakthrough was not until 60 years later, with anti-inflammatories (ibuprofen) and triptans (sumatriptan or Imitrex).

The last 15 years have produced a great deal of research on the serotonin mechanisms involved in headache, the genetics of migraine, blood flow abnormalities in the brain in headache patients, as well as a variety of other breakthroughs. Headache is now being viewed as a legitimate biological condition. I highly recommend Dr. McTavish's brilliant account, which accomplishes the difficult trick of entertaining while informing. 